\title{
Insufficient dimensional stability of bitumen sheets as a source of flat roof defects
}

\author{
Jan Plachý' ${ }^{1, *}$, Jana Vysoká $^{1}$, and Radek Vejmelka ${ }^{1}$ \\ ${ }^{1}$ Institute of Technology and Business in České Budějovice, 37001 České Budějovice, Czech \\ Republic
}

\begin{abstract}
One of the frequent sources of flat roof faults is failure of the top layer of a multilayer bitumen sheet system in cross-connections. One of the possible causes of this disorder is failure to observe technological discipline. The paper deals with how the full melting of the bitumen sheet influences its possible shrinkage during the roof exposure. Bitumen sheets with a polyester carrier which is not reinforced with fiberglass fibers are burdened with shrinkage effect. The preload is introduced into these belts during production. The aim is to show how is the effect on loosening the preload in the carrier layer with full-scale smelting during the realization of the waterproofing layer. The preload loosening experiment, expressed by the dimensional stability test according to ČSN EN 1107, was performed in a laboratory on two bitumen sheets.
\end{abstract}

\section{Introduction}

One of the frequent failures that arise on roof claddings is the release of bitumen sheets (BS) in transverse joints due to volume changes from the thermal load. These changes are manifested by the longitudinal shrinkage of the BS (Figure 1). One of the possible causes of this disorder is a failure to observe the technological discipline. In the case of multilayer systems, the top layer is not full-scale smelted on the substrate BS. The shrinkage effect is primarily due to the BS with a polyester carrier which is not reinforced with fiberglass fibers. The BS is preloaded during production, which gradually releases each additional thermal stress. This thermal stress is achieved by full-scale melting and exposure to sunlight. The aim of the paper is to show how the effect on the loosening of the preload in the carrier layer with full-scale smelting during the realization of the waterproofing layer.

The issue of volume changes BS has been dealt with in great detail [1] which, among other things, states that the most suitable for flat roofs are BS with composite carrier liner made of polyester fibers which are reinforced with fiberglass fibers. It also highlights the effect of the BS for volume changes. Another author [2] notes the force effects that are introduced into the carrier during the BS production. It is also possible to mention the group of authors [3], which notes the relation between the dimensional stability of the carrier and

\footnotetext{
* Corresponding author: plachy@mail.vstecb.cz
} 
the BS. In conclusion, the authors state that the influence of the covering material on the volume stability is small.

Although all authors [1,2] and [3] agree that composite inserts are the most suitable for roofing $\mathrm{BS}$, it is now possible to meet BS that contain a carrier only from polyester fibers. The reason for this composition is primarily economic aspects. None of the above mentioned authors dealt with dimensional stability of the BS after releasing the stress during full-scale smelting.

BS are tested for dimensional stability - volume changes according to ČSN EN 1107-1 [4]. UEAtc technical guide for the evaluation of roofing waterproofing systems comprising bitumen sheets modified by polymers APP or SBS [5] indicates that the values for dimensional stability have to be less than $0.5 \%$ in the case of multiple layer systems, and less than $0.3 \%$ for single layer systems. The abovementioned dimensional stability values for BS also take into account its requirements as ČSN 730605-1 [6]. The authors of this paper are of the opinion that full-surface smelting BS, which is intended for full-surface smelting application, has a decisive influence on the dimensional stability of the BS. Thus, a hypothesis was made that when the BS is fully smelted, most of the preload is loosened in the BS. The shrinkage value represents $50-75 \%$ of the total preload.

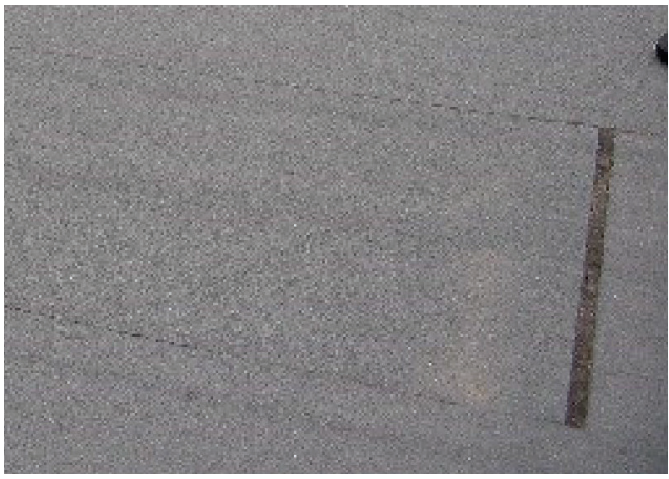

Fig. 1. Bitumen sheet failure.

\section{Material and methods of testing}

\subsection{Materials}

For the tests, two BS samples were selected with a polyester carrier with a different basis weight. Both BS samples are designated as the topsheet of a multilayer system. The mode of application of BS is selected for full-scale fusion, see Table 1.

Table 1. Bitumen sheets - Dimensions and characteristics. Signification: $\mathrm{E}-$ the mass modified by elastomers, PY - polyester fleece.

\begin{tabular}{|c|c|c|c|c|}
\hline \multirow{2}{*}{$\begin{array}{c}\text { Characteristics of } \\
\text { the test sample / } \\
\text { number of test } \\
\text { sample }\end{array}$} & $\begin{array}{c}\text { Modification } \\
\text { type of bitumen } \\
\text { coating matter }\end{array}$ & $\begin{array}{c}\text { Nominal } \\
\text { thickness [mm] }\end{array}$ & \multicolumn{2}{|c|}{ Reinforcement } \\
\cline { 4 - 5 } & E & 4.2 & material & Area weight $\left[\mathbf{g} / \mathbf{m}^{2}\right]$ \\
\hline T 180 80 & $\mathrm{E}$ & 5.2 & PY & 180 \\
\hline T 230 80 & & & & 230 \\
\hline
\end{tabular}




\subsection{Methods of testing}

The test specimens were tested according to EN 1107-1 [4]. This standard allows two methodologies to be used for testing - optical, which is more accurate [1,3] and mechanical. For economic reasons, the mechanical method was chosen using the sliding scale as shown in Figure 2. The exposure time of the test samples is at $80{ }^{\circ} \mathrm{C}$ for 24 hours, see [24]. Based on experience, see [7], further measurement intervals of 6, 12, 48, 72 and 96 hours were determined. The steady state in terms of dimensional stability was 96 hours. For each sample, nine test specimens were always prepared in the longitudinal direction of BS production. Since the major failures in this type of BS are achieved primarily in the longitudinal direction, they have not been tested in the transverse direction of the BS.

An increase in the number of test specimens from five to nine, which is prescribed [4], was carried out for better statistical evaluation. Samples simulating full-scale smelting were labeled with T $180 \mathrm{n} 80$ and T $230 \mathrm{n} 80$. The simulation of full-scale smelting was achieved by heating the BS with a propan-butane burner (PB burner) after the measuring points were prepared from a distance of $100 \mathrm{~mm}$ (about 5 seconds during the melting of the separation film) for a short time. The PB burner with a diameter of $60 \mathrm{~mm}$ and a power of $58 \mathrm{~kW}$ was used. The measuring points were protected against flame by an aluminum foil.

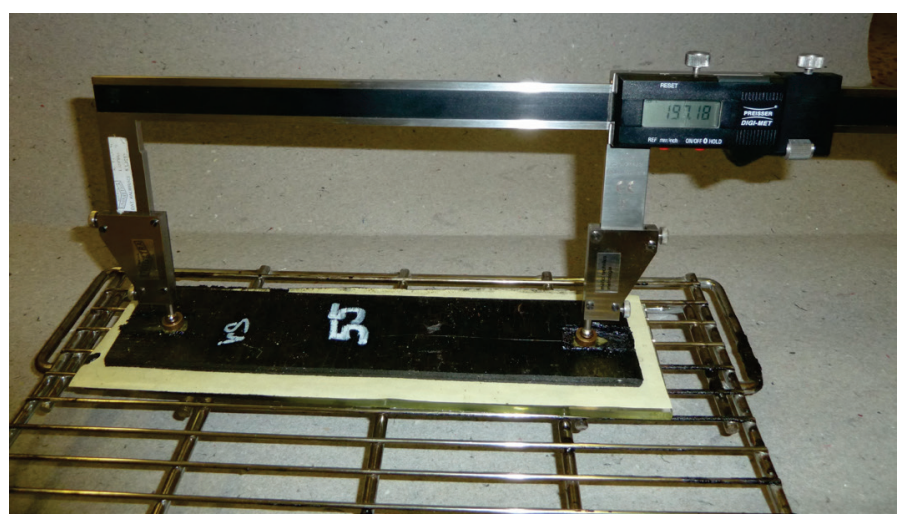

Fig. 2. The testing specimen for the dimensional stability of bitumen sheets according to ČSN EN 1107-1 [4].

\subsection{Evaluation}

Four types of samples were processed for evaluation. Nine test specimens were tested for each sample. The resulting value of the dimensional stability is given as the mean of the valid measurements, including the standard deviation, which tells how the values of the statistical set differ from the mean value. Was evaluated:

- percentage of initial preload applied to bitumen sheet for samples T180 n80, T $230 \mathrm{n} 80$ which are released by heating the bitumen sheet by PB burner

- changes in the dimensional stability of the bitumen sheet in time-dependence for samples T180-80, T230 80, where $24 \mathrm{~h} / 80^{\circ} \mathrm{C}$ exposure was determined as the reference temperature according to ČSN EN 1107-1 [4], the dimensional stability of the bitumen sheet at this temperature represented $100 \%$

- determining the dimensional stability of the bitumen sheet in relation to the requirements of ČSN 730605-1 [6]. 


\section{Results}

The measurement results are shown in Figure 3. The standard deviations are collected in Table 2.

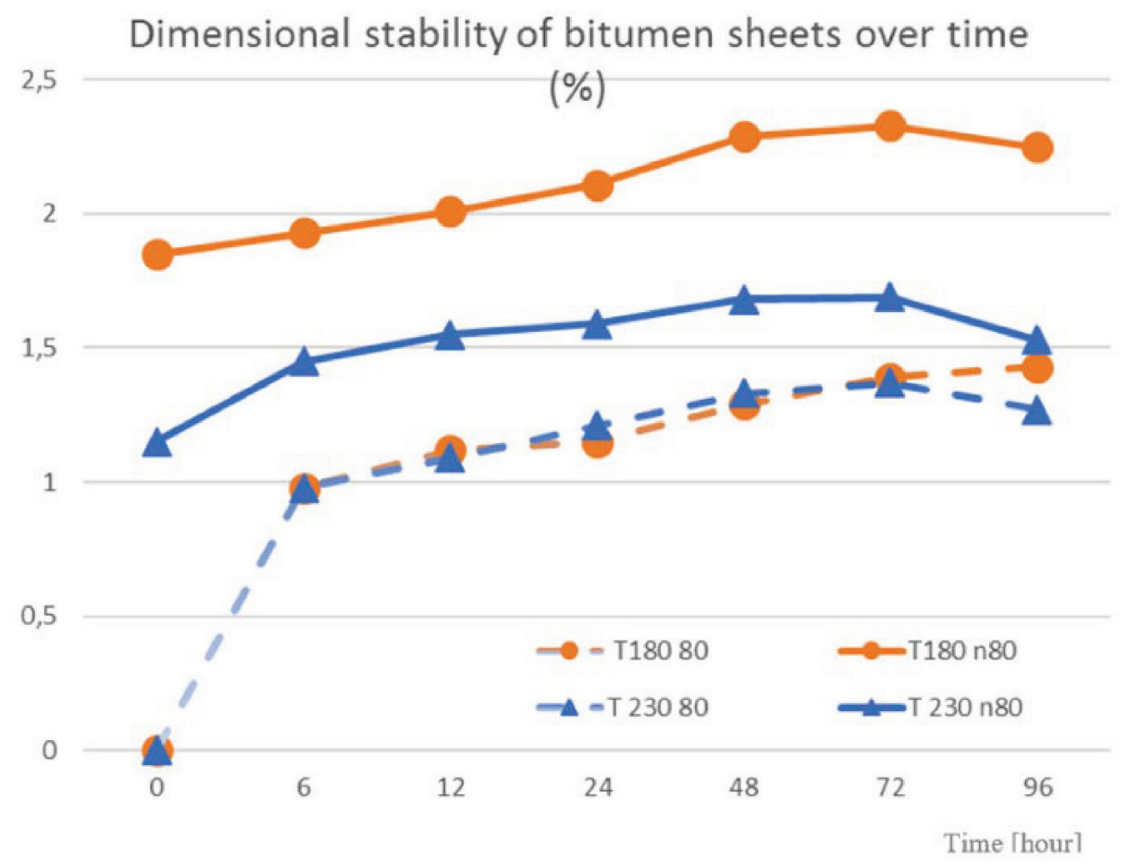

Fig. 3. The dimensional stability of bitumen sheets over time.

Table 2. Standard deviations.

\begin{tabular}{|c|c|c|c|c|c|c|c|}
\hline $\begin{array}{c}\text { Sample/exposition } \\
{[\mathbf{h}]}\end{array}$ & $\mathbf{0}$ & $\mathbf{6}$ & $\mathbf{1 2}$ & $\mathbf{2 4}$ & $\mathbf{4 8}$ & $\mathbf{7 2}$ & $\mathbf{9 6}$ \\
\hline T180 80 & & 0.206 & 0.232 & 0.236 & 0.198 & 0.194 & 0.2 \\
\hline T180 n80 & 0.356 & 0.368 & 0.372 & 0.256 & 0.373 & 0.363 & 0.378 \\
\hline T 230 80 & & 0.115 & 0.109 & 0.0092 & 0.161 & 0.145 & 0.102 \\
\hline T 230 n80 & 0.124 & 0.143 & 0.131 & 0.127 & 0.114 & 0.119 & 0.119 \\
\hline
\end{tabular}

\section{Discussion}

The hypothesis asserting that $50-75 \%$ of the total preload will be released when the test specimen is heated by the PB burner, has been confirmed. For sample T180 n80, 79.4\% of overall shrinkage was achieved. For sample T230 n80, $68.0 \%$ of overall shrinkage was achieved. For both samples, maximum shrinkage was achieved after 72 hours. It is possible to assume that another thermal exposure already exerted an extension of the carrier. The shrinkage value in the case of a larger basis carrier liner is smaller, which can be explained by introducing less deformation in the production of $\mathrm{BS}$, which is stronger thanks to the carrier liner.

The results transferred to Figure 4 demonstrate that the test procedure according to ČSN EN 1107-1 [4] shows that, depending on the type of carrier, there is still $15-24 \%$ shrinkage of the bitumen sheet. Conversely, more than $80 \%$ shrinkage after 24 hours according to 
ČSN EN 1107-1 [4] is achieved after 6 hours of exposure. Depending on the overall shrinkage, the value after 6 hours represents about $70 \%$ of the overall shrinkage.

From the point of view of the comparison of the results with the requirements of the standard ČSN 730605-1 [6], all samples had a significantly higher shrinkage than the required $0.5 \%$. Samples that have not been heated by the T180 80, T 23080 PB burner have shrunk values of $1-1.5 \%$. If the samples T180 n80, T $230 \mathrm{n} 80$ after heating the PB burner are evaluated, the shrinkage is at the tolerance limit of $0.5 \%$. In the case of exposure taking 24 hours the samples meet the standard requirement according to [6] see Table 3.

Table 3. The dimensional stability of bitumen sheets samples after heating with propan-butane burner.

\begin{tabular}{|c|c|c|c|c|c|c|c|}
\hline $\begin{array}{c}\text { Sample/exposition } \\
{[\mathbf{h}]}\end{array}$ & $\begin{array}{c}\text { Requirement } \\
\text { according to } \\
{[\mathbf{6}]}\end{array}$ & $\mathbf{6}$ & $\mathbf{1 2}$ & $\mathbf{2 4}$ & $\mathbf{4 8}$ & $\mathbf{7 2}$ & $\mathbf{9 6}$ \\
\hline $\mathbf{T 1 8 0} \mathbf{n 8 0}$ & 0.5 & 0.08 & 0.16 & 0.26 & 0.44 & 0.48 & 0.4 \\
\hline T 230 n80 & 0.5 & 0.3 & 0.4 & 0.44 & 0.53 & 0.54 & 0.38 \\
\hline
\end{tabular}

By comparing the shrinkage values of all samples, it is interesting to note that the T180 80 , T 23080 samples at $80^{\circ} \mathrm{C}$ do not remove most of the preload that is introduced into the $\mathrm{BS}$ during production. This result is determined by the temperature at which BS production takes place. This temperature is up to $180^{\circ} \mathrm{C}$, see [4]. On the other hand, the PB flame temperature at smelting, although acting in the short term, reaches $1100 \pm 100{ }^{\circ} \mathrm{C}$.

\section{Effect of time exposure on dimensional stability of bitumen sheets}

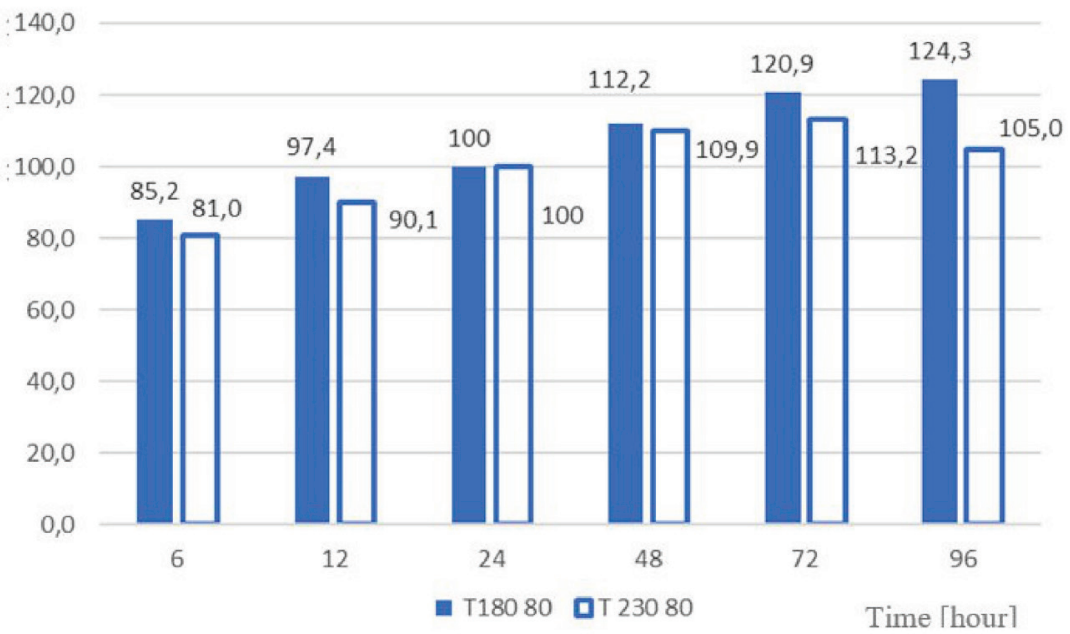

Fig. 4. The effect of time exposure on the dimensional stability of BS.

\section{Conclusion}

In conclusion, it is possible to state that in the case of bitumen sheets intended for the topsheets in a multilayer system with a non-glass fiber reinforced polyester liner and intended for full-scale smelting, the full-scale smelting is decisive for loosening the preload produced during the production of BS. 
Test results according to [4] showed that the exposure of 24 hours could theoretically be reduced to 6 hours because it is only a value for comparison between BS products. The test procedure in [4] applies to samples loosely laid on the substrate. However, this process is used in [8] for topsheets of bitumen sheets without any difference in application to the substrate.

In the next phase of the research, the attention will be paid to the measuring time interval and to bitumen sheets with composite carrier liners made of glass fiber reinforced polyester.

\section{References}

1. P. Malych, Volume changes of bitumen coatings. Volume changes of bitumen membranes (University of Technology in Bratislava, Faculty of civil engineering, Bratislava, 2001)

2. J. Plachý. Volume changes of bitumen sheets (Roof Symposium, Bratislava, 2010)

3. J. G. Lopes, J. R. Correia, M. X. B. Construction and Building Materials 25 (1), 3229$3235(2011)$

4. $\check{C} S N$ EN 1107-1 Flexible sheets for waterproofing - Part 1: Bitumen sheets for roof waterproofing - Bitumen sheets for roof waterproofing - Determination of dimensional stability (Prague, 2000)

5. The European Union for Agrément (UEAtc). UEAtc technical guide for the assessment of roof waterproofing systems made of reinforced APP or SBS polymer modified bitumen sheets (UEAtc, Paris, 2001)

6. ¿ CSN 730605-1 Waterproofing of construction works-Flexible sheets for waterproofing - Requirements for use of bitumen sheets

7. J. Plachý, Bitumen sheet joints under the influence of temperature and time in the composition of single-membrane roofs (Brno University of Technology, Faculty of civil engineering, Brno, 2005)

8. ČSN EN 13707. Flexible sheets for waterproofing - Reinforced bitumen sheets for roof waterproofing - Definitions and characteristics (Prague, 2014) 